\title{
THE SAMPLING OF SULFUR DIOXIDE IN AIR WITH IMPREGNATED FILTER PAPER
}

\author{
C. HUYGEN \\ National Institute of Public Health, Utrecht (The Netherlands)
}

(Réceived July ${ }_{4}$ th, 1962)

The most widely used devices for the sampling of gaseous atmospheric pollutants are impingers and bubblers. These absorbers have some disadvantages which are most felt in field work, such as fragility and the difficulty of handling the liquid content. It was therefore considered desirable to use solid absorbers. STRATMANN ${ }^{1}$ developed an interesting method for the determination of sulfur dioxide in which the gas is adsorbed on silica gel; it is later desorbed in the laboratory at a high temperature and reduced to hydrogen sulfide, which can be determined by very sensitive methods. The STRATMANN method is, however, rather elaborate and there seem's to be no constant supply of the special silica gel which is difficult to prepare.

In this paper a method is presented for the collection of sulfur dioxide using filter. paper impregnated with solutions; most of the advantages of liquid and solid absorbents are combined. Previous workers ${ }^{2,3}$ have utilized the coloration or bleaching of impregnated filter paper by sulfur dioxide for its determination. In our method; however, the sulfur dioxide is collected very efficiently on the paper and can be washed out in the laboratory and determined by any convenient method. Thus a higher precision and sensitivity can be attained.

The possibility of collecting gaseous air pollutants on filter paper was suggested by the observation that normal wet filter paper supported on sintered glass is capable of retaining a relatively large part of the sulfur dioxide present in the air that is drawn through it. This interfered with the determination of sulfuric acid mist in the atmosphere, for which the arrangement was intended.

In preliminary tests, we tried filter paper prepared with a large percentage of silica gel, such as that used by OKKERSE for the determination of certain organic vapours. In experiments with these filters highly efficient collection was obtained with filters which also contained sodium hydroxide. Surprisingly, common filter paper treated in the same way was not only as efficient but the sulfur dioxide once absorbed proved to be quite resistant to atmospheric oxidation.

Further improvements gave an impregnated filter paper with very useful properties, such as high efficiency of collection under almost all circumstances and good stability of the collected sulfur dioxide.

An application that suggested itself was the semi-continuous sampling of sulfur dioxide with a filter-tape air-sampler; this was found to be possible and is the more 
important because there is a tendency to express MAC-values for air pollutants as the mean over, e.g., $30 \mathrm{~min}$.

It appears that an analogous use can be made of impregnated filter paper for the collection of air pollutants other than sulfur dioxide; successful applications to the sampling of hydrogen fluoride and hydrogen sulfide will be reported at a later date.

\section{EXPERIMEN'TAL}

The impregnated filter may be considered as an absorber in which a small amount of liquid is finely divided on a solid support, hence the air that is drawn through the absorber will have a much greater effect than in the case of impingers. For this reason, the influence of the humidity and the carbon dioxide of the air on the collection efficiency of the filters and on the stability of the retaincd sulfur dioxide was investigated.

A second important point is the oxidation velocity of retained sulfur dioxide. Several impregnating liquids were investigated in these two respects and the best were studied more fully.

Impregnating liquids. Solutions of the following substances in water were tested.

(I) Potassium hydroxide, potassium carbonate and potassium bicarbonate: carbonate and bicarbonate were included because the hydroxide changes slowly to these salts in contact with air; the potassium salts were chosen because they are more hygroscopic than the corresponding sodium salts.

(2) The same salts with the addition of glycerol: glycerol is said to have a stabilizing effect on sulfur dioxides; also it is hygroscopic.

(3) The same salts with the addition of potassium chloromercurate: the latter is known to stabilize sulfite" ${ }^{3}$. In the case of hydroxide extra potassium iodide, and in the case of carbonate extra potassium chloride, was required to keep the mercury complex in solution. Of course this had an adverse effect on the stability of the sulfite complex.

(4) The same salts as in (3) with the addition of glycerol.

(5) The same salts as in $(I)$ with the addition of triethanolamine, which was found to be preferable to glycerol in some respects.

(6) Calcium chloride in order to see whether alkali was indispensable.

(7) Calcium chloride with sodium chloromercurate.

Filters. Whatman No. $I$; diam. $5.5 \mathrm{~cm}$. These were prepared by bathing them in the impregnating solutions, excess of which was squeezed out with a common household wringer. After this procedure the filters contained about $13 \mathrm{mg}$ of solution $/ \mathrm{cm}^{2}$. Finally they were dried in an oven, usually at $I I 0^{\circ}$.

Bicarbonate filters were prepared by keeping carbonate filters for a few days in a carbon dioxide-rich atmosphere.

Sampling procedure. The air containing sulfur dioxide was drawn through the filters usually at a rate of $\mathrm{I} \mathrm{m}^{3} / \mathrm{h}$. The filters were clamped between plastic rings in a holder. The rings restricted the effective diameter of the filters to $4 \mathrm{~cm}$ and sometimes two or three filters were used in series in the same holder. The air flows were measured by rotameters and/or dry test meters.

Air streams with known or approximately known quantities of sulfur dioxide were prepared in two ways:

(a) by means of a dosing stopcock and mixing chamber. This gave an unknown but Alual. Chim. Acla, 28 (1963) 349-360, 
rather high concentration during a short time. The total quantity of sulfur dioxide was a few hundred micrograms. The device was used in the determination of collection efficiencies.

(b) by mixing a small stream of sulfur dioxide measured by a rotameter with a large stream $\left(r, 000 \mathrm{~m}^{3} / \mathrm{h}\right)$ of air, measured by means of a plate-orifice meter. Control of the relative humidity of the air. This was achieved in two ways:

$(a)$ by diminishing the pressure. The humidity was then calculated from the residual pressure and the humidity and pressure of the laboratory air. This procedure is not quite correct because the collection efficiency may depend on the pressure via the diffusion velocity. However, diffusion in the gas phase docs not seem to be a limiting factor. Nevertheless, this procedure was used only in the preliminary investigations.

(b) by mixing measured streams of laboratory air and air completely dried by means of silica gel. This procedure was checked by means of a wet and dry bulb hygrometer and was found to be sound.

Determination of the sulfur dioxide absorbed. The sulfur dioxide was determined by the $p$-rosaniline method ${ }^{2}$ in the washings of the filters after addition of an amount of acid just sufficient to neutralize the alkaline content of the filters.

Collection efficiency. The efficiency $\eta$ of the filters was determined in two ways:

(a) from the quantities of sulfur dioxide, $F_{1}$ and $F_{2}$ respectively, found on the first and second of two filters in series, by means of the formula

$$
\eta=1-\mid F_{2} / F_{1}
$$

This is only approximately correct because there is a slight difference in the humidity and velocity of the air at the two filters, caused by the pressure drop over the first filter. Therefore this procedure was used only in the preliminary investigations.

$(b)$ from the quantities of sulfur dioxide, $F$ and $I$, found respectively on a filter and an impinger in series, by the formula:

$$
\eta=\frac{l}{F+1.04 I}
$$

The factor I.04 was calculated from the collection efficiency of the impinger, which was found to be $96 \%$, independent of the humidity.

Determination of stability. The stability of the absorbed sulfur dioxide was determined by storing filters with known quantities of sulfur dioxide in a desiccator over dry silica gel or over water saturated with sodium chloride to maintain a humidity of $75 \%$. The quantities of sulfur dioxide contained in the filters were calculated from the volume of air drawn through them, the sulfur dioxide concentration of the air being determined in a parallel test.

\section{RESULTS}

It was found that at high humidities all filters had sampling efficiencies of at least $99 \%$ except those that were impregnated with a solution containing $25 \%$ calcium chloride in water or in $30 \%$ sodium chloromercurate solution. These absorbed less than $10 \%$ of the quantity of sulfur dioxide drawn through them. The efficiency of the others dropped markedly below 100\% at relative humidities below 30\%. In Table I are shown the efficiencies found at $25 \%$ humidity; the figures are the mean of two 
TABLE I

SAMPLING IFFICIENCINS OF IMPREGNATED FILTER PAPFY AT $25 \%$ RELATIVE HUMIDITY

\begin{tabular}{|c|c|c|}
\hline & Impregualing solution & Efficicucy \\
\hline Solutions in water & 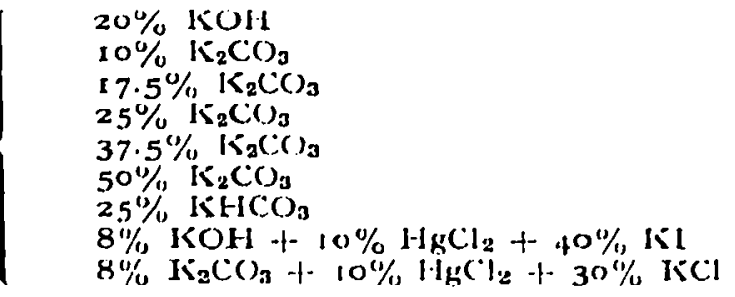 & $\begin{array}{r}80 \\
48 \\
68 \\
59 \\
52 \\
54 \\
5 \\
51 \\
10\end{array}$ \\
\hline $\begin{array}{l}\text { Solutions also } \\
\text { containing } 10 \% \\
\text { glyccrol }\end{array}$ & 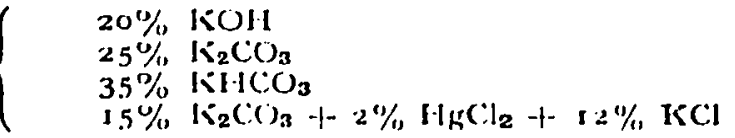 & $\begin{array}{l}95 \\
95 \\
93 \\
80\end{array}$ \\
\hline $20 \%$ ISOI- $-10 \%$ & ctha & gx \\
\hline
\end{tabular}

TAJ3I,E II

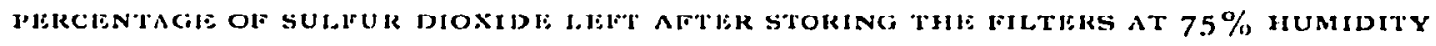

\section{Impregibatiug solution}

ISOLI

$\mathrm{IV}_{2} \mathrm{CO}_{3}$

KOUI-I +t glycerol

$\mathrm{Ni}_{2} \mathrm{CO}_{3}+$ gilycerol

$\mathrm{K}_{2} \mathrm{CO}_{3}+\mathrm{HgCl}_{2}+\mathrm{KCCl}+$ glycerol

$\mathrm{KOOH}+\mathrm{HgCl}_{2}+\mathrm{ISI}+\mathrm{glycurol}$

KOH + trictlanolamine

\begin{tabular}{|c|c|c|c|c|c|}
\hline \multicolumn{6}{|c|}{ Tirnc of sloratere (alceys) } \\
\hline$\stackrel{1}{1}$ & 3 & + & 7 & 14 & 28 \\
\hline 93 & $\rightarrow$ & $\cdots$ & 0 & - & - \\
\hline 42 & 10 & - & 0 & - & $\rightarrow$ \\
\hline 96 & - & $-\infty$ & 0 & $\longrightarrow$ & - \\
\hline 70 & - & 17 & 0 & - & - \\
\hline-- & $r_{5}$ & 50 & 3.5 & 20 & 9 \\
\hline $\begin{array}{c}7 \\
\text { see }\end{array}$ & $\overline{\mathbf{I}}$ & 3 & - & - & - \\
\hline
\end{tabular}

YA 13I.SIII

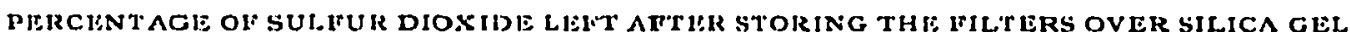

\begin{tabular}{|c|c|c|c|c|c|c|}
\hline \multirow{2}{*}{ Impregrating solution } & \multicolumn{6}{|c|}{ Tine of storege (elays) } \\
\hline & $I$ & 7 & 9 & $2 I$ & 28 & 51 \\
\hline 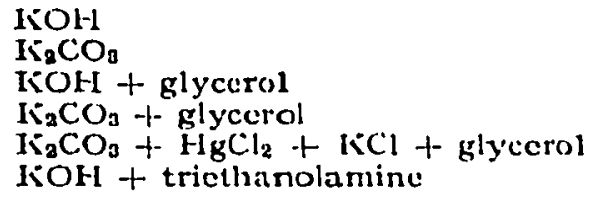 & $\begin{array}{r}105 \\
98 \\
96 \\
99 \\
-\end{array}$ & $\begin{array}{r}106 \\
101 \\
107 \\
106 \\
97 \\
\end{array}$ & $\overline{-}$ & $\begin{array}{l}- \\
- \\
103 \\
100\end{array}$ & $\begin{array}{l}104 \\
103 \\
10.5 \\
103 \\
\end{array}$ & $\overline{-}$ \\
\hline
\end{tabular}

determinations. It can be seen from lable I that filters impregnated with solutions containing glycerol or triethanolamine gave the most satisfactory results. Apparently, the efficiency did not clepend very much on the total qunntity of potassium carbonate. Filters with a high quantity of alkali were stiff when dry and very wet at high humidity, but had a high sampling capacity. Impregnating solutions containing $20 \%$ potassium hydroxide or $25 \%$ potassium carbonate gave a rcasonable compromise. 
In Tables II and III are given the results of experiments on the rate of atmospheric oxidation of the sampled sulfur dioxide. These figures are incomplete but show that there was no advantage in the use of impregnating solutions containing mercury compounds. The other filters were equally suitable when kept dry. In a humid atmosphere, the potassium hydroxide filters were markedly better, but even these could not be kept for longer than one day if the sulfur dioxide was to be determined as such. Of course it could always be determined as sulfate. To summarize: of the impregnating solutions investigated, those containing $20 \%$ potassium hydroxide ancl ro\% glycerol or triethanolamine were the most suitable; they had the best collection efficiencies at low humidity and the best stabilizing effect on the retained sulfur dioxide. They were therefore studied further.

Figure 1 shows that the rate of oxidation of sulfur dioxide absorbed on filters was low at first but increased later. It was considered that the effect might hatve been connected with the uptake of carbon clioxicle, but the results of an experiment conducted in a carbon dioxide-free atmosphere suggested no such connection and this line of investigation was not further followed.

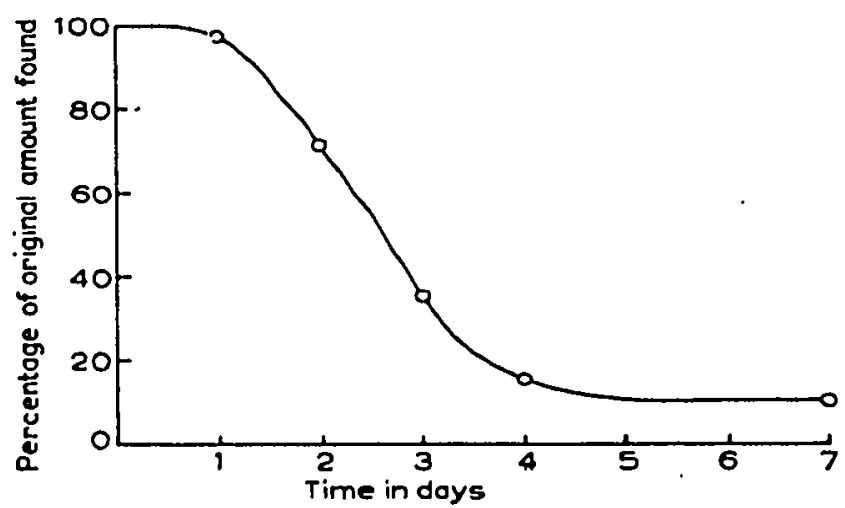

Fig. 1. Oxidation of $\mathrm{SO}_{2}$ sampled on liOl1-trictlanolamine filters.

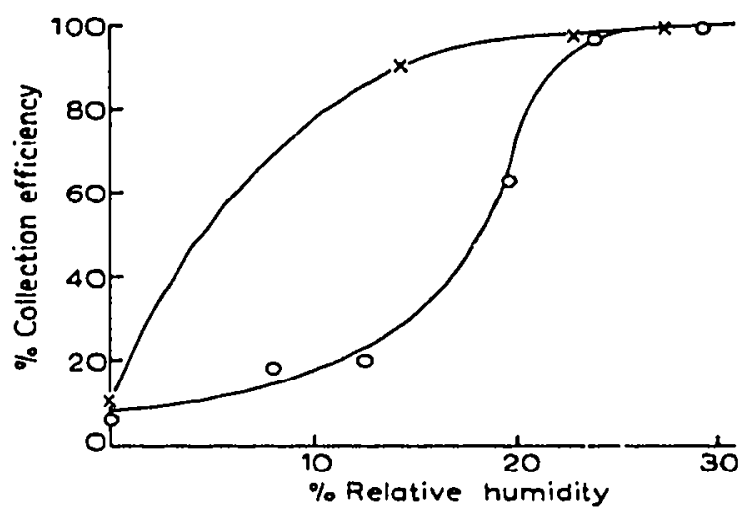

Fig. 2. Dependence on the humidity of the collection efficiency of filters impregnated with KOH ind glycarol (O) and KOH and tricthimolamine $(x)$.

In Fig. 2 are given the results for the determinations of the collection efficiencies of the two best kinds of filter in relation to the humidity. The efficiencies of the potassium hydroxide-glycerol filters after the hydroxide had changed to carbonate and bicarbonate were also determined. These efficiencies followed mainly the same lines as those of the original filters, but, parallel with an increase in the percentage of carbon clioxide, efficiencies became to an increasing extent dependent on the total quantity of sulfur dioxide. The potassium bicarbonate-glycerol filters, for instance, showed an efficiency of $9 \mathrm{I} \%$ at a humidity of $17 \%$ with a total collected quantity of $300 \mu \mathrm{g}$ of sulfur dioxide, but an efficiency of only $79 \%$ at a humidity of $37 \%$ with $2.5 \mathrm{mg}$ of sulfur dioxide collected.

The hydroxide on the filters changed to bicarbonate only very slowly. Table IV summarizes some of the results. No doubt the rate of carbon dioxide uptake would vary with the humidity. These results were obtained at a humidity of about $50 \%$.

Another effect of the restriction in the amount of absorbing solution was a limited sampling capacity, i.e. the sampling efficiency was dependent on the total collected 
TABLIE IV

COMPOSITION OI THE ALKALI OV THE FILTLRS IN \% KQUIVAJJNT AFTER DRAWING AIR TIROUGH

\begin{tabular}{|c|c|c|c|c|}
\hline $\begin{array}{c}\text { Impregnating } \\
\text { solution }\end{array}$ & $\begin{array}{l}\text { Time of treatment } \\
\text { with air (days) }\end{array}$ & $\%$ OH - & $1 \% \mathrm{CO}_{\mathrm{y}} 2-$ & $1 \% \mathrm{HCO}_{3}-$ \\
\hline $\begin{array}{l}\mathrm{KOH}+ \\
\text { glycerol }\end{array}$ & $\begin{array}{r}0 \\
1 \\
10\end{array}$ & $\begin{array}{r}93 \\
0 \\
0\end{array}$ & $\begin{array}{l}7 \\
91 \\
78\end{array}$ & $\begin{array}{r}0 \\
9 \\
22\end{array}$ \\
\hline $\begin{array}{l}\text { kof }-1 \\
\text { tricthatnol- } \\
\text { amine }\end{array}$ & $\begin{array}{c}0 \\
1 \\
10\end{array}$ & $\begin{array}{r}80, \\
0 \\
0\end{array}$ & $\begin{array}{l}14 \\
80) \\
50\end{array}$ & $\begin{array}{l}0 \\
11 \\
50\end{array}$ \\
\hline
\end{tabular}

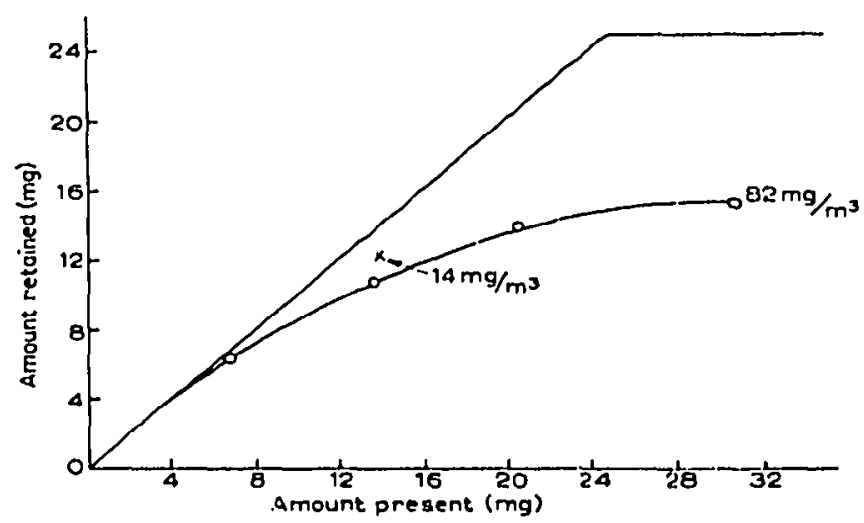

Fig. 3. Quantity of $\mathrm{SO}_{2}$ collected compared with the cluantity present in the air clrawn through the filters.

quantity of sulfur dioxide. Figure 3 shows this dependence at a humidity of $45 \%$; the straight lines represent the ideal roo\% efficiency until all the hydroxicle is consumed according to the reaction

$$
2 \mathrm{KOI}+\mathrm{I}+\mathrm{SO}_{2} \rightarrow \mathrm{K}_{2} \mathrm{SOJ}+\mathrm{H}_{3} \mathrm{O}
$$

It can be seen from Fig. 3 that the efficiency depends not only on the total quantity of sulfur dioxide, but also on its concentration.

The above-mentioned experiments cover sufficient ground to give an idea of the possibilities and limitations of the impregnated filter paper method.

Applications. To investigate the technique more fully, we devised what we term a "limits test". In these tests the filters were subjected to a combination of the most adverse circumstances under which the method can still be used. These limiting conditions were chosen rather arbitrarily in such way that in practice it should normally be possible to remain on the siffe side. The conditions were as follows:

(a) Concentration of sulfur dioxide: $10 \mathrm{mg} / \mathrm{m}^{3}$,

(b) Total quantity of sulfur dioxide: 10\% of the theoretical filter capacity according to $(x)$,

(c) Relative humidity: $30 \%$ and $25 \%$ for the potassium hydroxide-glycerol and the potassium hydroxide-triethanolamine filters, respectively,

(d) Air velocity: $501 / \mathrm{cm}^{2} / \mathrm{h}$. 
This "limits test" was used to study four possible applications of the impregnated filter paper method, viz. to replace impingers or bubblers in: $(I)$ short-time measurements, lasting, e.g., $30 \mathrm{~min}$; (2) medium-time measurements, lasting, e.g., one day; (3) long-time measurements lasting, e.g., ten days; (4) sequential samplers.

In the testing of application $(I)$ the test was carried out immediately after preparation of the filters; after the test the filters were kept in a desiccator for 3 days before analysis (representing a week-end).

Application (2) was tested in two ways: (a) The test was applied immediately after the preparation of the filters as in $(I)$ but then laboratory air was drawn through the filters for I day before they were kept dry for 3 days; $(b)$ air was drawn through for one day, then the test was applied and then the filters were kept dry for 3 days.

Tests of application (3) were done as for (2b) except that air was drawn through the filters for Io days.

In order to calculate the collection efficiency, three filters in scries were used, the last one being a freshly prepared potassium hydroxide--tricthanolamine filter. In order to caiculate the loss of sulfur clioxide during the thrce days the concentration was determined in parallel with freshly prepared potassium hydroxicle-triethanolamine filters. All tests were clone in duplicate.

To illustrate application (4), an A.T.S.I. automatic smoke sampler was modified in such way that the filter tape was always in a closed compartment dried with silica gel. The tape itself was impregnated with potassium hydroxide-triethanolamine solution before use. The sampler was set to take $30-\mathrm{min}$ samples of outdoor air during ro days. Each working day the limits test was applied to two successive spots by feeding air containing about to $\mathrm{mg} \mathrm{SO} / \mathrm{m}^{3}$ during two successive $15-\mathrm{min}$ periods. However, the humidity was always higher, sometimes much higher than $30 \%$. The filter tape was analysed after another ro days in a desiccator.

Г人I3I.L V

\begin{tabular}{|c|c|c|c|c|c|}
\hline \multirow[b]{2}{*}{ linpreg'natiub solution } & \multicolumn{2}{|c|}{ Day's air arawiz through } & \multicolumn{2}{|c|}{$\% \mathrm{SO}_{2}$ on } & \multirow{2}{*}{$\begin{array}{l}\% \text { found } \\
\text { after } 3 \\
\text { days. }\end{array}$} \\
\hline & $\begin{array}{c}\text { Before } \\
\text { lest }\end{array}$ & $\begin{array}{c}\text { Aftior } \\
\text { lest }\end{array}$ & $\begin{array}{l}\text { rirst } \\
\text { filler }\end{array}$ & $\begin{array}{l}\text { First pluts } \\
\text { second fille' }\end{array}$ & \\
\hline $\mathrm{KOH}+$ glycerol & $\begin{array}{c}0 \\
1 \\
0 \\
10\end{array}$ & $\begin{array}{l}0 \\
0 \\
1 \\
0\end{array}$ & $\begin{array}{l}92 \\
53 \\
92 \\
37\end{array}$ & $\begin{array}{l}99.8 \\
89 \\
99.8 \\
6.5\end{array}$ & $\begin{array}{l}91 \\
99 \\
\text { ror.5 } \\
75\end{array}$ \\
\hline $1 \mathrm{KOH}+$ trietlanolamine & $\begin{array}{c}0 \\
1 \\
0 \\
10\end{array}$ & $\begin{array}{l}0 \\
0 \\
1 \\
0\end{array}$ & $\begin{array}{l}92 \\
81 \\
90 \\
42\end{array}$ & $\begin{array}{l}99.7 \\
97 \\
99.9 \\
65\end{array}$ & $\begin{array}{l}99 \\
97 \\
97 \\
39\end{array}$ \\
\hline
\end{tabular}

From Tables II and V, it can be concluded that the impregnated filter method is most useful for short-time measurements. Sampling times of one day can be used if the humidity is not too low; if it is low then two filters in series and/or a lower linear air velocity must be used. The same measures can be taken on long-time tests when medium concentrations (more than $0.1 \mathrm{mg} / \mathrm{m}^{3}$ ) are to be expected. At high 
humidities it may be safer to determine the sulfur dioxide as sulfate, instead of as sulfur dioxide if long sampling times (one day or more) are used.

The difficulties encountered in the r-day measurements are also found in the Io-day measurements, but here they have grown in importance. It is no longer possible to determine the sulfur dioxide as such and the peak and mean concentrations must be even lower or the air velocity slower.

The results of the measurements concerning application (4) were as follows: the mean of the absolute deviations from the calculated quantities of sulfur dioxide on the spots through which sulfur dioxide was clrawn, was $5.7 \%$, and the deviation of the mean from the calculated mean was $2.7 \%$. No reason was found to suppose that the absorbed sulfur dioxide was not $100 \%$ preserved. The mean concentration found on the 464 clean spots was $\mathrm{r} \mu \mathrm{g} / \mathrm{m}^{3}$; the mean of the absolute differences between the concentrations found and their mean was $0.2 \mu \mathrm{g} / \mathrm{m}^{3}$.

Hardly any indication of contamination of the "clean" spots by the "dirty" spots was found: two clean spots showed concentrations of respectively $66 \mu \mathrm{g} / \mathrm{m}^{3}$ and $20 \mu \mathrm{g} / \mathrm{m}^{3}$.

The results of some other experiments, mainly about details in the practical application of the method, are discussed below.

Washing of filters. There are two acceptable ways of washing the sulfur dioxide out of the filters. The first is to put the filter on a sintered-glass support and draw the wash liquid through it. The second is to put the filter in a beaker with the wash liquid and wash by shaking or stirring. In the first method the wash solution must not be acidic if accurate results are to be obtained. This excludes the direct use of the $p$-rosaniline reagent. A quantity of $\mathrm{I} \mathrm{ml}$ of wash solution $/ \mathrm{cm}^{2}$ of filter is sufficient; in onc experiment only $0.06 \%$ of the sulfur dioxide was found in a second wash. In the second method, water containing an amount of acid equivalent to the alkali of the filter may be used; again it is not advisable to usc the p-rosaniline reagent directly. In both methods, a solution of sodium chloromercurate can be used to increase the permissible time-lapse between washing and analysis. This also makes it possible to use a wash solution containing the neutralizing amount of acid in the first method and the $p$ rosaniline reagent in the sccond method. It must be noted that triethanolamine binds mercury by complex formation.

Effect of alkali content of filters on p-rosaniline method. The optical density obtained for a given quantity of sulfur dioxide in the p-rosaniline method depends on the acidity of the final solution; thus if the alkali of the filters is not neutralized exactly, an error arises. If the filters are impregnated to contain $0.07 \mathrm{mmol}$ of potassium hydroxide $/ \mathrm{cm}^{2}$ and an amount of $\mathrm{Iml}$ of wash solution $/ \mathrm{cm}^{2}$ is used, the amount of alkali is just about equivalent to the amount of acid present in the reagent to be added. If extra neutralizing acid is not added, a high optical density is obtained. However, if the amount of cxtra acid is double the necessary amount, the quantity of sulfur dioxide found (0.I5 $\mu \mathrm{g} / \mathrm{cm}^{2}+5 \%$ ) is low. A variation of not more than Io\% in the amount of alkali is readily obtainable and the resulting error is acceptable. To be on the safe side, it is advisable to use a somewhat higher final acidity than that normally obtained.

Storage and drying of zinised filters. Filters that are not used within a short time after preparation must be stored under such conditions that they do not take up any carbon dioxide; this can be done in a desiccator over silica gel. It was found that the filters 
did not take up an important amount of carbon dioxide even after eight weeks. Bicarbonate appeared to change back to carbonate under these conditions. When filters were kept as advised and used when still dry, they were slightly less effective than moist filters; efficiencies of respectively 92 and $95 \%$ were found at a concentration of $15 \mathrm{mg} / \mathrm{m}^{3}$ during I min at a humidity of $35 \%$.

Effect of linear air velocity. One would expect the effect of, for instance, halving the linear air velocity to be about the same as doubling the concentration or doubling the filter thickness. The results obtained so far are not sufficient in number to allow certainty on this point. Normally our linear air velocity was about $15 \mathrm{~cm} / \mathrm{sec}$, but efficiencies of over $99 \%$ could be obtained at high humidities at ro times this rate.

Recovery of known $\mathrm{SO}_{2}$ concentrations. A known concentration (see EXPERIMENTAL) of about $8 \mathrm{mg}$ of sulfur dioxide $/ \mathrm{m}^{3}$ was determined in 8 replicate determinations by the impregnated filter method. The variation about the mean of the results was $4 \%$ and the deviation of the mean from the calculated value was $\mathrm{I} .3 \%$, which was slightly better than expected.

Practical use. We have used the filter method for about a year in the ficld under all sorts of weather conditions, comparing it with the impinger method, mostly in $30-\mathrm{min}$ or 6o-min measurements. The sulfur dioxide concentrations measured ranged between $0.02 \mathrm{mg} / \mathrm{m}^{3}$ and $\mathrm{r} \mathrm{mg} / \mathrm{m}^{3}$. The mean absolute difference of the values obtained by the two methods was $0.015 \mathrm{mg} / \mathrm{m}^{3}$ or $6 \%$. The difference in the mean values was 0.01 $\mathrm{mg} / \mathrm{m}^{3}$ or $4 \%$, the filters giving the lowest value. The difference was not significant at the $95 \%$ level. A systematic error of $\mathrm{x} \%$ may have arisen from the fact that the air flow was dried after the impingers, but before measurement.

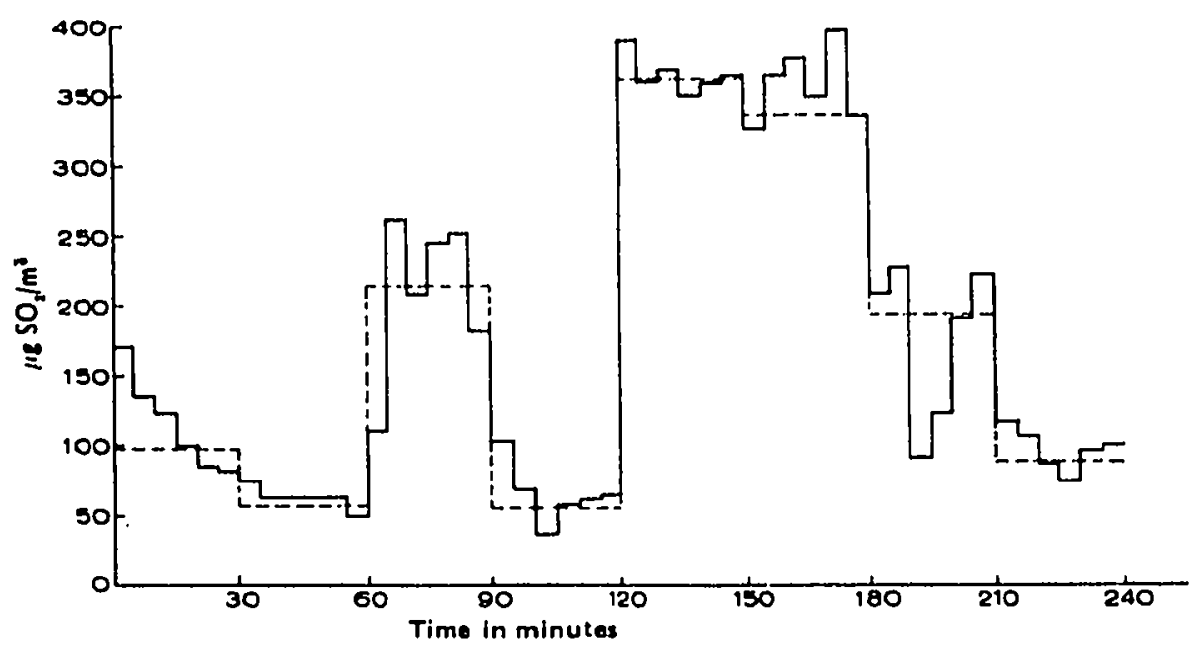

Fig. 4. Comparison between values obtained by atumatic sampling (5-min values) and by normal filter method (30-min values).

Fig. 4 shows a comparison between 5 -min values obtained with a Gelman automatic filter-tape sampler and $30-\mathrm{min}$ measurements by the new filter method. In Table VI the latter are also compared with the mean $30-\mathrm{min}$ values calculated from the 5 -min values. The agreement is satisfactory. 
TABI,IE VI

COMPARISON OF RIESULTS BY AUTOMATIC AND NORMAL PHLTEK METHODS

\begin{tabular}{|c|c|c|c|}
\hline \multicolumn{2}{|c|}{ Mean 3o-min $\mathrm{SO}_{2}$ concentration (mg/mi") } & \multicolumn{2}{|c|}{ Absolute difference } \\
\hline Alulomeatic sumpler & Normat filler methesd & $\left(\mu m^{\prime} / m^{3}\right)$ & $(\%)$ \\
\hline 0.110 & 0.097 & 19 & 20 \\
\hline 0.002 & $0.05^{\circ}$ & 6 & I I \\
\hline 0.210 & 0.215 & 5 & 2 \\
\hline 0.065 & 0.054 & 11 & 20 \\
\hline 0.360 & 0.362 & 4 & i \\
\hline 0.320 & 0.337 & $1 i$ & 3 \\
\hline 0.177 & 0.10 .1 & 17 & 9 \\
\hline 0.003 & 0.088 & 5 & 6 \\
\hline Mcill 0.177 & 0.175 & 10 & 9) \\
\hline
\end{tabular}

When the humidity was very high we found that the filters lost strength because of the uptake of water. The danger of splitting the filters can be eliminated by supporting them, by warming the air, by lowering its pressure, or by using two filters on top of each other.

\section{JISCUSSION}

The more important conclusions which can be drawn from the present work are as follows.

(I) Filter paper impregnated with solutions of potassium hyclroxide with added glycerol or triethanolamine has a high sampling efficiency for sulfur dioxide in air provicled that the following conditions are fulfilled:

(a) relative humiclity not lower than $30 \%$,

(b) sulfur dioxide concentration not higher than $10 \mathrm{mg} / \mathrm{m}^{3}$,

(c) total quantity of sulfur dioxide collected not more than equivalent to $10 \%$ of the alkali of the filter,

(d) linear velocity of the air drawn through the filters not more than $15 \mathrm{~cm} / \mathrm{sec}$.

One of these limits may be overstepped if the other conditions are adjusted accordingly.

(2) If the sampling time is longer than one day, the sulfur dioxide concentration must be lower than ro $\mathrm{mg}^{\prime} \mathrm{m}^{3}$ or the air velocity less than $15 \mathrm{~cm} / \mathrm{sec}$.

(3) Sulfur clioxide absorbed by the filters is very resistant to oxidation if the filters are kept dry.

(4) If the sampling time is more than one day, it is safer to determine the sulfur dioxide as sulfate instead of as such.

From these points it is clear that impingers can be replaced by the impregnated filter method. Its application in automatic samplers also merits consicleration. Automatic filter-tape air-samplers are commercially available and can be used with impregnated filter tape for the sampling of sulfur dioxide if so modified that the rolls of tape are kept dry. Full advantage of the automatic sampling cannot be taken unless it is followed by automatic analysis; for this purpose we are now trying to construct an automatic analyser that will punch out the sample spots, add wash solution and reagents by means of automatic pipets, measure the optical density of the resulting 
liquid and print out the concentration of the air pollutant. The latter will be made possible by using a spectrophotometer with automatic compensation of the light absorption by means of a moving wedge. The wedge will be coupled mechanically to a printing rotation counter. A time interval of $30 \mathrm{sec}$ between two analyses is planned. Thus the analyser will be able to keep pace with ten automatic samplers set to take 30-min samples. It might seem that ten samplers taking 5-min samples, in combination with an automatic analyser, will give the equivalent of ten of the commonly used recording air analysers for a much lower price. However, this is not quite true because the recording instruments give the value of the concentration in a much shorter time. On the other hand the filter analyser can give the mean value of the concentration in digital form, which is an advantage if one is interested in, for instance, 30-min values rather than peak values.

The most important limitation of the impregnated filter paper method seems to be the low ef ficiency at low humidities. It is true, at least in Holland, that an outdoor humidity below $30 \%$ is very seldom measured, but when the outdoor temperature is low, the relative humidity may decrease considerable if the air becomes warmer before filtration, for instance, in a mobile laboratory. In such cases, the filter holders must be placed outside or - less good - the air must be humidified before filtration.

There are four factors influencing the collection efficiency: diffusion in the gas phase, adsorption on the liquid surface, chemical reaction with the absorption solution, and diffusion in the liquid phase. The humidity, air velocity, total quantity of sulfur dioxide and its concentration each influence these factors, but it is difficult to determine experimentally the exact effect of each variable. However, the results indicate that diffusion in the gas phase is not a limiting factor, so that it would be more important to use other kinds of impregnating solutions rather than other kinds of filter paper.

Other points still to be investigated are the influence on the collection efficiency and the stability of absorbed sulfur dioxide, of other air pollutants such as oxidants, nitrogen dioxide, hydrogen sulfide and dust (especially iron oxides). However, the usefulness of the method appears to be sufficiently well established to justify publication of the results obtained so far.

\section{SUMMARY}

A method is suggested for the sampling of sulfur dioxide in air with impregnated filter paper instead of bubblers. The best aqucous impregnating solution contained potassium hydroxicle with glycerol or tricthanolamine. The possibilities and limitations of the method are cliscussed. High collection efficiencies (over $95 \%$ ) were obtained at relative humiditics above $25 \%$. Collected sulfur dioxide was stable for at least several wecks when the filters were kept dry after the sampling. The method is especially suited for short-time measurements and for automatic sampling with smoke samplers.

\section{RIESUMiE}

Une méthocle est proposce pour le prélivement d'anhydricle sulfureux dans l'atmosphère cn utilisant du papier a filtrer imprégné. Les meilleurs résultats ont ite obtenus avec des solutions aqueuses d'hydroxyde de potassium, additionnécs de glycérol ou de triéthanolaminc. Cette méthode convient spécialement pour des déterminations de courte durée ct pour des prélèvenents automatiques.

\section{ZUSAMMENFASSUNG}

Es wird cine Methode beschrieben zur Entnahme von Luftproben mit Hilfe von imprägniertem Filterpapier. Als Imprägnierflüssigkeiten eignen sich besonders wässrige IFaliumbydroxydlösungen.

Anal. Chim. Acla, $28\left(\mathrm{IgG}_{3}\right) 349-360$ 
dic noch Glycerin oder Triäthanolanin enthalten. Anwendungsmöglichkciten und Grenzen der Methode werclen diskutiert. Sie eignet sich besonders für kurzfristige Messungen und für automatische l'robecntnahmen in Rauchprïgeraten.

TRELERENCES

1 H. Sirkathann, Mikrochim. Acta, (1954) 008 .

3 H. F. J,IDDlisl, Analyst, 80 (1955) gor.

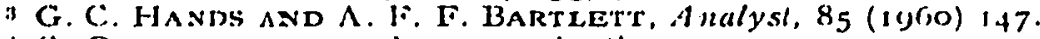

4 C. OKKERsie, personal communication.

s J'. HaLlisk, J. Soc. Chem. Ind., 38 (1019) 52 \%.

"J. W. Wrest AN D G. C. GAikis, Anal. Chem. 28 (1050) 1810.

7 A. Sirigman, J. Soc. Chem. Snd.,Gi $(1942)$ I 8.

Anal. Chim, Acta, $28(1963) 349-3(j)$

\title{
POLAROGRAPHY OF URANIUM IN IAACTATE MEDIUM
}

\author{
S. C. SARAIYA AND A. K. SUNDARAM \\ Analytical Division, Atomic Jinergy Establishment Trombay, Bombay (India)
}

(Received June gth, 1962)

Polarography of uranium is interesting from the point of view of the disproportionation of uranium(V) formed by reduction of uranium(VI) at the electrode $1-4$. A study of this phenomenon in the presence of certain complexing agents has already been described ${ }^{5}$; the present paper reports the polarography of uranium in lactate medium.

\section{Apparaties}

EXPLIRIMNTAL

Current-potential curves were measured manually on a Cambridge Pen-Recording polarograph at a sensitivity of $\mathrm{I} / \mathrm{I} 5$ corresponding to $0.5 \mu \mathrm{A}$ per clivision. An $\mathrm{H}$-type cell with a saturated calomel electrode (S.C.E.) as the reference clectrode was used for the measurements at $30 \pm 0.5^{\circ}$ with deaerated solutions. The capillary characteristics were: $m=0.80 \mathrm{mg} \mathrm{sec}-1$ and $t=4.8 \mathrm{sec}$ at $-0.5 \mathrm{~V}$ vs. S.C.E. in the supporting clectrolyte used.

\section{Chemicals}

Reagent grade chemicals were used. The preparation of the uranium solution has been clescribed earlier ${ }^{5}$. Sodium lactate was determined by passing an aliquot of the solution through a column of a cation exchanger (Dowex 50 ) and titrating the cffluent with standard alkali. The ionic strength was maintained at $x .0$ by the addition of requisite amounts of sodium perchlorate. Thymol ( $1 \cdot 10^{-3} \%$ in the final solution) was used as the maximum suppressor.

\section{RESULTS AND DISCUSSTON}

The polarographic behaviour of uranium in lactate medium was studied at different 